\title{
Hierarchical structure of stream ecosystems: consequences for bioassessment
}

\author{
Iwona K. Ciesielka $\cdot$ Robert C. Bailey
}

Received: 28 October 2005/Revised: 10 May 2006/ Accepted: 23 November 2006/Published online: 5 April 2007 (C) Springer Science+Business Media B.V. 2007

\begin{abstract}
It has long been recognized that communities and their ecosystems are structured at several, nested spatial scales. But identifying the appropriate scale(s) to collect, analyse and interpret data to answer specific questions about ecosystems has been a vexing problem for ecologists. We collected observations of the benthic invertebrate community and its environment in 10 primarily agricultural tributary streams of the Thames River in southwestern Ontario, Canada. Within each stream we sampled two reaches, in each reach we sampled three riffles, and in each riffle we took three kick samples of invertebrates and characterized the substrate environment. We also characterized the habitat at each of the 20 reaches (10 streams $\times 2$ reaches/stream). Most of the variability in the stream invertebrate community structure (as described with taxonomic richness and the biotic index of tolerance, as well as by the Bray-Curtis distance of the community composition from the mean at a spatial scale) was at larger spatial scales of among streams and between riffles. Much of the substrate and habitat variation was also at the larger spatial scales, as
\end{abstract}

Handling editor: R. Norris

I. K. Ciesielka · R. C. Bailey ( $₫)$

Department of Biology, The University of Western

Ontario, London, ON, Canada N6A 5B7

e-mail:drbob@uwo.ca were correlations between the biota and the environment of the benthic invertebrate community. We concluded that for the purposes of bioassessment, characterization of one reach per stream is sufficient, at least in this context, for describing a stream and evaluating its health.

Keywords Hierarchical structure $\cdot$ Stream ecosystems · Bioassessment $\cdot$ Benthic invertebrates

\section{Introduction}

Stream ecologists have long struggled with defining what they feel is the correct scale for their research. It has been effectively argued that streams should be treated like aquatic landscapes (Wiens, 2002), and like all of landscape ecology, the appropriate scale of sampling and analysis depends on the research question. But the exact link between question and scale has never been very clearly elaborated. Variation in the processes and patterns of the stream environment has an obvious spatial and temporal hierarchy (Frissell et al., 1986), with ramifications for component communities such as the macroinvertebrates (Boyero \& Bailey, 2001; Parsons et al., 2003; Townsend et al., 2004). Minshall and Peterson (1985) proposed that at small spatial $(\mathrm{mm}$ to $\mathrm{cm})$ and temporal ( $\mathrm{ms}$ to $\mathrm{h}$ ) scales, the interrelated 
hydrodynamics and substrate of a stream determine the distribution of individuals, and by extension, the structure of communities. At larger $(\mathrm{km})$ scales of stream reach and basin, factors such as discharge, channel size, riparian vegetation, and both surficial and bedrock geology often are more important in determining community structure (e.g., Yates \& Bailey, 2006). Longitudinal, cumulative effects of these larger scale factors give rise to the longitudinal zonation of rivers (Vannote et al., 1980). It is also at this larger spatial scale of the reach or the entire stream that bioassessment usually asks the question of whether or not human activity has affected the stream.

Assessing the effects of human activity on ecosystems at more than one scale may yield complex or even contradictory results. For example, bank erosion at a given point in a stream may be caused by agricultural activity at a drainage basin scale, channelization at the reach scale, cattle access at a very small scale, or a combination of all three (Imhof et al., 1996). The ecological effects of the erosion may only be measurable at a very small scale or may alter the structure of the entire downstream ecosystem. The complexity of scales in the environment and effects on the biological communities make understanding the stream ecosystem difficult, and environmental assessment and remediation very challenging (Hawkins et al., 1993). Sometimes even the most basic question, "Is sampling one reach of a stream adequate to characterize the stream for environmental assessment?", is impossible to answer.

In this study, we quantified the hierarchical variation in the structure of macroinvertebrate communities (including their pollution tolerance) and their substrate environments in 10 major tributary streams of the 6th order Thames River in temperate, northeastern North America. We then correlated the structure of the macroinvertebrate community with its multi-scale environment, and determined from this an efficient strategy for sampling streams in bioassessments.

\section{Methods}

The Upper Thames River Catchment Area (UTRCA) encompasses $3,500 \mathrm{~km}^{2}$ in southwestern
Ontario, Canada. The climate is humid continental, with most annual precipitation in either April or November. The gently rolling area has mostly sandy, loamy soils, and much of the extensive corn, soybean, and winter wheat croplands have subsurface tile drainage, with attendant water quality problems in the receiving streams (Barton, 1996). Ten, primarily agricultural, 4th order streams in UTRCA were selected for this study of the hierarchical structure of stream ecosystems (Table 1). Two geomorphologically distinct reaches within each stream (UP and DN), at least $1 \mathrm{~km}$ and at most $3 \mathrm{~km}$ apart on the stream channel were chosen based on accessibility to private lands. Three, longitudinally consecutive riffles (UP, MD, DN) were sampled within each reach. Three, parallel points within each riffle (LT, MD, RT) were sampled as described below.

Each of the 20 reaches (10 streams $\times 2$ reaches/ stream) was visited in random order between 29 June and 20 July 1998. At a reach, sampling was carried out beginning with the downstream riffle and working upstream to minimize longitudinal disturbance. A $5 \mathrm{~m}$ (downstream to upstream) kick sample was taken at the three parallel points within each riffle with a $500 \mu \mathrm{m}$ D-net. The washed debris from each kick sample was preserved in $70 \%$ ethanol and then physical and chemical habitat measurements were made. Substrate was visually assessed for each kick sample point as per cent bedrock, cobble, pebble, gravel, sand, silt, and clay. None of the points had bedrock substrate so analyses were limited to boulder-sized and smaller particles. Following macroinvertebrate sampling and substrate assessment, each reach was scored with a modification of the EPA Habitat Assessment for high gradient streams that considered available cover, embeddedness of the substrate, velocity/depth regime, channel alteration, scouring and deposition, frequency of riffles, bank stability, bank vegetation, and riparian vegetation (Plafkin et al., 1989).

Macroinvertebrate samples with their associated debris were subsampled using a 100 cell Marchant box (Marchant, 1989), such that a minimum of 200 individuals were used to calculate the diversity (using $\mathrm{S}$, taxonomic richness), tolerance (using BI, Hilsenhoff's (1987) biotic 
Table 1 Major tributary streams of the Upper Thames River that were sampled in this study

\begin{tabular}{llllc}
\hline Stream & $\begin{array}{l}\text { Basin } \\
\text { Area } \\
\text { (ha) }\end{array}$ & $\begin{array}{l}\text { Urban } \\
\%\end{array}$ & $\begin{array}{l}\text { Agriculture } \\
\%\end{array}$ & $\begin{array}{l}\text { Forest } \\
\%\end{array}$ \\
\hline Avon River & 13,903 & 17 & 72 & 11 \\
Dingman Creek & 15,588 & 22 & 58 & 20 \\
Fish Creek & 5,919 & 0.45 & 90 & 9.1 \\
Gregory Creek & 4,655 & 0.96 & 93 & 6.2 \\
Kintore Creek & 3,230 & 0.80 & 87 & 12.4 \\
Medway Creek & 7,769 & 1.0 & 93 & 6.3 \\
North Branch & 14,565 & 0.46 & 85 & 14.3 \\
$\quad$ Creek & & & & \\
North Thames & 32,596 & 2.0 & 91 & 6.4 \\
$\quad$ River & & & & 7.6 \\
Phelan Creek & 3,657 & 1.1 & 91 & 25 \\
Waubuno Creek & 8,169 & 2.5 & 73 & \\
\hline
\end{tabular}

The basin area was determined by watershed delineation (using ArcGIS) of the reach that was furthest downstream. Proportion of different land cover caetgories was determined from 1983 land cover confirmed by analysis of ortho-imagery from 2000 (Upper Thames River Conservation Authority, unpublished data)

index), and proportional composition of the community at a given spot in the riffle. The invertebrates were identified to genus using Merritt and Cummins (1995), Thorp and Covich (1991), Weiderholm (1983), and Wiggins (1995). All Chironomidae were mounted on glass slides using CMC-9AF mounting medium from Master's Chemical Company, Inc. Worms (Oligochaeta, Turbellaria), mites (Arachnida), and leeches (Hirudinea) were identified to Class only.

We summarized the variation and covariation of substrate properties among the 180 observations $(10$ streams $\times 2$ reaches/stream $\times 3$ riffles/ reach $\times 3$ kick points/riffle) with Principal Component Analysis (PCA) of the covariance matrix of the proportion of the substrate in different size categories. Examination of a scree plot indicated that the first two gradients were interpretable, so Principal Component (PC) scores for the first two axes were calculated for each observation. Variation and covariation of EPA habitat assessment scores from 20 observations $(10$ streams $\times 2$ reaches/stream) were also summarized with PCA of the covariance matrix of the nine habitat descriptors. A scree plot showed three interpretable gradients in habitat assessment descriptors, so PC scores for the first three axes were calculated for each of the 20 observations.
Nested Analysis of Variance (ANOVA) was used to partition variability in $\mathrm{S}$ and $\mathrm{BI}$ of the macroinvertebrate communities among streams, reaches within streams, riffles within reaches, and points within a riffle. The nested variation in community composition was characterized using a modification of Underwood and Chapman's (1998) technique. Total variation in composition among the 180 communities was described with the Bray-Curtis distance (minimum $=0$, maximum $=1$ ) between each community and the overall mean proportion of each taxon across the 180 communities. For each scale in the hierarchy (streams, reaches within streams, riffles within reaches, and points within riffles) we then calculated the median of Bray-Curtis distances between units at given scale and the mean community for that scale.

Nested ANOVA was also used to partition variation in substrate (Substrate PC1, PC2) into stream, reach, riffle, and sampling point components, and habitat assessment scores (Habitat PC1, PC2, PC3) between stream and reach components. The covariation of the macroinvertebrate community and its environment was partitioned among the spatial scales using a nested ANOVA. Correlations between richness (S) and pollution tolerance (BI) of the biota, and the substrate (Substrate PC1, PC2) at the stream, reach, riffle, and point scales were calculated using the sum of squares and cross products matrix for each scale. Similarly, correlations between richness and pollution tolerance of the biota, and the habitat assessment scores (Habitat PC1, PC2, PC3) were calculated for the stream and reach scales, since only one habitat assessment was done at each reach.

\section{Results}

There was a total of 135 taxa found at the 180 sampling sites, with a median of 31 taxa observed per kick sample $($ minimum $=18$, maximum $=45)$. Hilsenhoff's Biotic Index of tolerance to organic pollution, calculated for a community at a given kick sample, varied from 1.50 (excellent water quality) to 5.96 (fair water quality). 
Table 2 Substrate particle size variability among 180 sampling points $(10$ streams $\times 2$ reaches/stream $\times 3$ riffles/reach $\times 3$ points)

\begin{tabular}{lllcrr}
\hline Descriptor & Minimum $\%$ & Maximum \% & Median \% & Substrate PC1 & Substrate PC2 \\
\hline Boulder & 0 & 65 & 3 & 0.022 & $\mathbf{- 0 . 8 8 2}$ \\
Cobble & 0 & 75 & 35 & $\mathbf{- 0 . 8 5 3}$ & 0.167 \\
Gravel & 2 & 50 & 15 & $\mathbf{0 . 4 4 7}$ & 0.304 \\
Pebble & 5 & 50 & 20 & 0.002 & 0.302 \\
Sand & 0 & 50 & 6 & 0.117 & 0.050 \\
Silt & 0 & 50 & 5 & 0.239 & 0.086 \\
Clay & 0 & 60 & 0 & 0.027 & -0.027 \\
\hline
\end{tabular}

Structure coefficients (Pearson correlation between PC score and original variables) are given in Substrate PC columns. Bold faced PC coefficients (absolute value $>0.4$ ) were used in interpreting the PC axes

There was considerable variation among kick sample points in the substrate characteristics (Table 2). The dominant particle size was cobble (median 35\%), with very little sand, silt, and clay present at any point (median total of sand, silt, and clay $=11 \%)$. Two principal components explained almost $75 \%$ of the variation in substrate descriptors. Substrate PC1 contrasted sampling points with gravel and some silt and sand present (positive values) to riffle areas dominated by cobble (negative values). Substrate PC2 contrasted riffle areas with gravel and pebble substrate (positive values) to those with boulders (negative values).

Total habitat assessment scores varied widely from 61 to 142 out of a maximum of 165 (Table 3). Substrate embeddedness, channel alteration, and frequency of riffles showed the greatest variability among reaches. Habitat PC1 contrasted reaches with little substrate cover, high embeddedness of substrate, lots of fine sediment deposition, and little riffle habitat (negative values) to those with plenty of cover, low embeddedness and deposition of fines, and plenty of riffle habitat (positive values). Habitat PC2 was a gradient of little variation in velocity/depth regimes within the reach and poorly developed riparian vegetation (negative values), to reaches with variable velocity/depth regimes and well developed, treed riparian vegetation (positive values). Habitat PC3 contrasted reaches with unstable banks and poor riparian vegetation (negative values) to those with stable banks and developed riparian vegetation (positive values).

Nested ANOVA showed over $75 \%$ of the variability in both taxonomic richness (S) and tolerance of the community to pollution (BI) was among streams (Table 4). Variation among kick samples within a riffle was a distant second place in variation of richness $(17 \%)$, while variation between reaches of a stream was the second most important component for the biotic index of

Table 3 EPA Habitat assessment scores (derived from Plafkin et al., 1989) as estimated for each of the 10 streams $\times 2$ reaches/stream $=20$ reaches

\begin{tabular}{lccccrr}
\hline Descriptor & Minimum & Maximum & Median & Habitat PC1 & Habitat PC2 & Habitat PC1 \\
\hline Available substrate cover (out of 20) & 5 & 20 & 16 & $\mathbf{0 . 4 1 5}$ & 0.102 & 0.012 \\
Substrate embeddedness(out of 20) & 0 & 20 & 16 & $\mathbf{0 . 5 9 2}$ & 0.044 & 0.033 \\
Velocity/depth regime(out of 20) & 6 & 18 & 10 & 0.086 & 0.527 & -0.386 \\
Channel alteration(out of 15) & 0 & 14 & 9 & 0.195 & 0.060 & -0.019 \\
Scouring and deposition(out of 15) & 6 & 14 & 12 & $\mathbf{0 . 4 1 8}$ & -0.207 & -0.228 \\
Frequency of riffles(out of 15) & 0 & 15 & 14.5 & $\mathbf{0 . 4 4 3}$ & 0.242 & 0.053 \\
Bank stability(out of 20) & 6 & 20 & 18 & 0.222 & -0.386 & $\mathbf{0 . 6 5 4}$ \\
Bank vegetation (out of 20) & 16 & 20 & 18 & -0.050 & -0.026 & 0.131 \\
Riparian vegetation(out of 20) & 6 & 20 & 10 & -0.092 & $\mathbf{0 . 6 7 4}$ & $\mathbf{0 . 5 9 1}$ \\
Total(out of 165) & 61 & 142 & 123.5 & & &
\end{tabular}

Structure coefficients (correlation between PC score and original variables) are given in Habitat PC columns. Bold faced PC coefficients (absolute value $>0.4$ ) were used in interpreting the PC axes 
Table 4 Variance (and \% of total) of nested effects for S (richness, number of invertebrate taxa), BI (biotic index, a measure of the average tolerance of community members to organic pollution)

\begin{tabular}{|c|c|c|c|c|}
\hline $\begin{array}{l}\text { Response } \\
\text { Variable }\end{array}$ & Among streams $(\mathrm{df}=9)$ & Between reaches $(\mathrm{df}=10)$ & Among riffles $(\mathrm{df}=40)$ & $\begin{array}{l}\text { Within } \\
\text { riffles }(\mathrm{df}=120)\end{array}$ \\
\hline S (richness) & $\begin{array}{c}\mathbf{6 0 . 7 6}(\mathbf{7 6} \%)(\mathrm{MS}=152.09 \\
\mathrm{F}=4.98, P=0.01)\end{array}$ & $\begin{array}{c}4.93(6 \%)(\mathrm{MS}=30.57 \\
\mathrm{F}=1.98, P=0.07)\end{array}$ & $\begin{array}{c}0.59(0.1 \%)(\mathrm{MS}=15.78 \\
\mathrm{F}=1.13, P=0.31)\end{array}$ & $\begin{array}{l}14.01 \\
\qquad(17 \%)(\mathrm{MS}=14.01)\end{array}$ \\
\hline $\begin{array}{l}\text { BI (biotic } \\
\text { index) }\end{array}$ & $\begin{array}{l}2.42(77 \%)(\mathrm{MS}=6.65 \\
\mathrm{F}=3.68, P=0.03)\end{array}$ & $\begin{array}{c}0.43(14 \%)(\mathrm{MS}=1.80 \\
\mathrm{F}=3.43, P<0.003)\end{array}$ & $\begin{array}{c}0.12(4 \%)(\mathrm{MS}=0.52 \\
\mathrm{F}=3.25, P<0.001)\end{array}$ & $\begin{array}{l}0.16 \\
\quad(5 \%)(\mathrm{MS}=0.16)\end{array}$ \\
\hline $\begin{array}{l}\text { Substrate } \\
\text { PC1 }\end{array}$ & $\begin{array}{c}0.04(2 \%)(\mathrm{MS}=6.54 \\
\mathrm{F}=1.01, P=0.49)\end{array}$ & $\begin{array}{c}1.88(81 \%)(\mathrm{MS}=6.47 \\
\mathrm{F}=7.90, P<0.001)\end{array}$ & $\begin{array}{l}0.21(9 \%)(\mathrm{MS}=0.82 \\
\mathrm{F}=4.34, P<0.001)\end{array}$ & $\begin{array}{l}0.19 \\
\quad(8 \%)(\mathrm{MS}=0.19)\end{array}$ \\
\hline $\begin{array}{l}\text { Substrate } \\
\text { PC2 }\end{array}$ & $\begin{array}{c}0.92(37 \%)(\mathrm{MS}=6.27 \\
\mathrm{F}=1.42, P=0.30)\end{array}$ & $\begin{array}{c}0.97(39 \%)(\mathrm{MS}=4.43 \\
\mathrm{F}=2.91, P=0.008)\end{array}$ & $\begin{array}{r}0.46(18 \%)(\mathrm{MS}=1.52 \\
\mathrm{F}=10.45, P<0.001)\end{array}$ & $\begin{array}{l}0.15 \\
\quad(6 \%)(\mathrm{MS}=0.15)\end{array}$ \\
\hline $\begin{array}{l}\text { EPA } \\
\quad \text { Habitat } \\
\text { PC1 }\end{array}$ & $\begin{array}{c}0.00(0 \%)(\mathrm{MS}=7.94 \\
\mathrm{F}=0.74, P=0.67)\end{array}$ & $10.75(100 \%)(\mathrm{MS}=10.75)$ & na & na \\
\hline $\begin{array}{l}\text { EPA } \\
\quad \text { Habitat } \\
\text { PC2 }\end{array}$ & $\begin{array}{c}\mathbf{5 . 8 1}(\mathbf{6 0} \%)(\mathrm{MS}=15.54 \\
\mathrm{F}=3.97, P=0.02)\end{array}$ & $3.91(40 \%)(\mathrm{MS}=3.91)$ & na & na \\
\hline $\begin{array}{l}\text { EPA } \\
\quad \text { Habitat } \\
\text { PC3 }\end{array}$ & $\begin{array}{c}2.08(22 \%)(\mathrm{MS}=11.61 \\
\mathrm{F}=1.56, P=0.25)\end{array}$ & $7.45(78 \%)(\mathrm{MS}=7.45)$ & na & na \\
\hline
\end{tabular}

The significance of each effect was tested relative to the nested effect in the column to its right. Bold faced component(s) of variance is(are) the most important scale(s) of variation for a given response variable

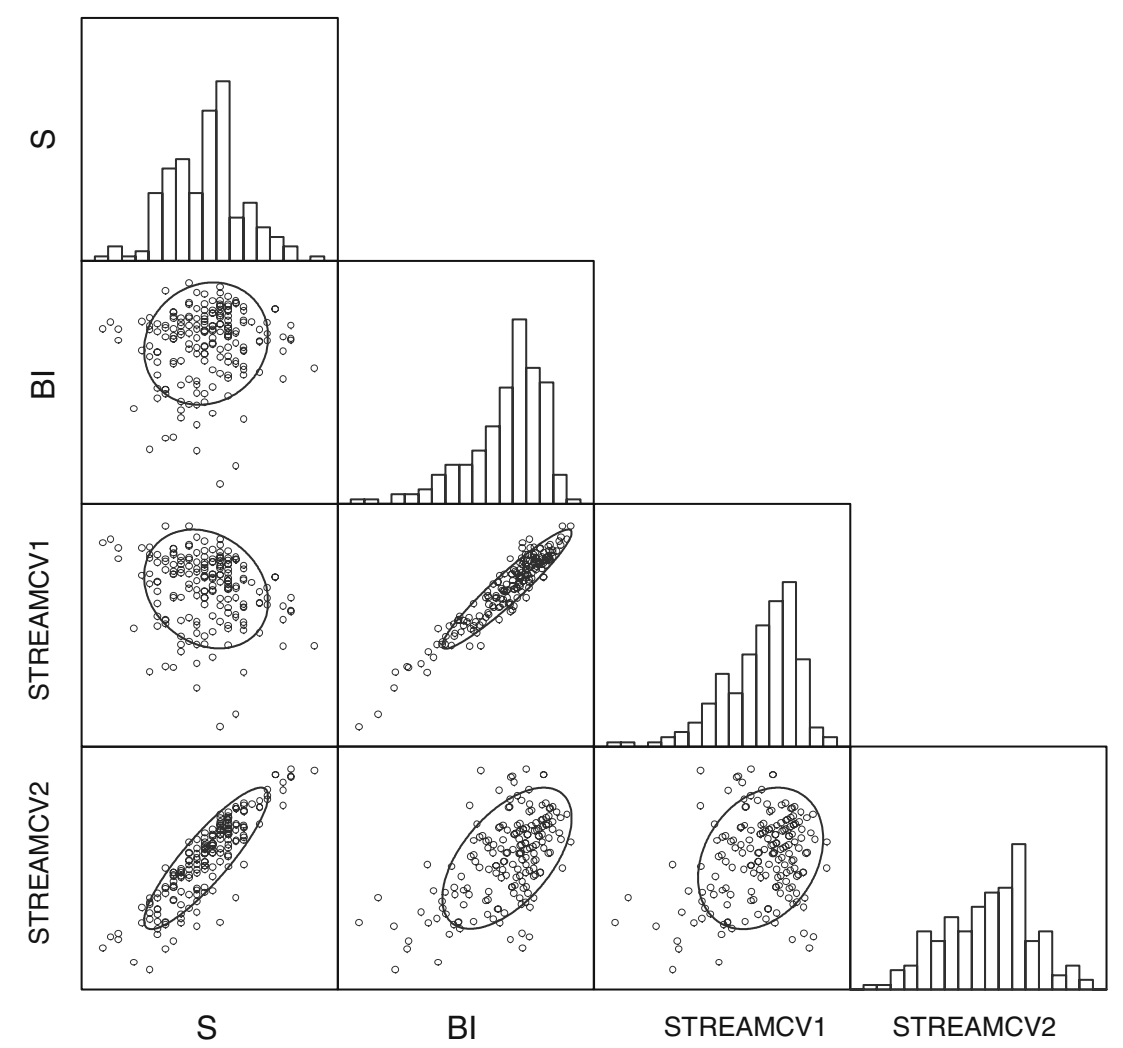

Fig. 1 Variation and covariation of benthic invertebrate community descriptors (S, BI) and the canonical variate scores that best describe variation among streams in communities (StreamCV1, StreamCV2) 


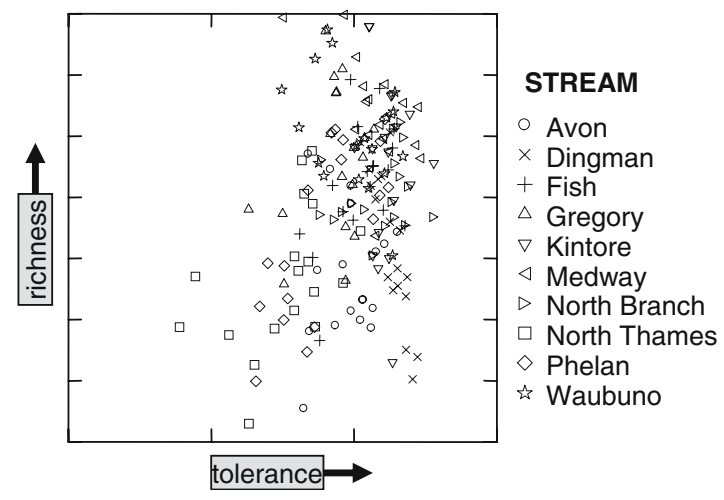

Fig. 2 Variation among streams in canonical variate scores that best describe variation among streams in communities (StreamCV1, StreamCV2)

tolerance to pollution (14\%). The multivariate gradients (known as canonical variates, $\mathrm{CVs}$ ) best distinguishing streams (Fig. 1) were most related to tolerance (Stream CV1) and richness (Stream CV2). When the communities from each stream were plotted using the first two canonical variate scores, a clear gradient of stream communities from those with fewer and less tolerant taxa (e.g., North Thames River) to those with a richer, more tolerant community (e.g., Medway Creek) was observed (Fig. 2).

As measured by the Bray-Curtis distance to the average community (minimum $=0$ for a community exactly like average community; maxi-

Table 5 Hierarchical variation in composition of macroinvertebrate communities as reflected by the Bray-Curtis distance $($ minimum $=0$, maximum $=1$ ) to the average community at a given scale

\begin{tabular}{lllllll}
\hline Scale & $n$ & minimum & maximum & median & mean \\
\hline Total & 180 & 0.100 & 0.958 & 0.467 & 0.485 \\
$\begin{array}{c}\text { Among } \\
\quad \text { streams }\end{array}$ & 10 & 0.263 & $\mathbf{0 . 4 7 4}$ & $\mathbf{0 . 3 4 1}$ & $\mathbf{0 . 3 5 7}$ \\
$\begin{array}{c}\text { Between } \\
\quad \text { reaches }\end{array}$ & 20 & 0.080 & 0.383 & 0.171 & 0.191 \\
$\quad$ within \\
$\begin{array}{c}\text { streams } \\
\begin{array}{c}\text { Among riffles } \\
\text { within } \\
\text { reaches }\end{array}\end{array}$ & 60 & 0.100 & 0.376 & 0.162 & 0.176 \\
$\begin{array}{c}\text { Among points } \\
\text { within riffles }\end{array}$ & 180 & $\mathbf{0 . 0 7 3}$ & 0.375 & 0.167 & 0.173 \\
\hline
\end{tabular}

Bold faced values were the extreme observed (e.g., largest median distance to average community was observed at the among stream scale) mum = 1 for a community very different from average community), the composition of the communities varied mainly among streams (Table 5). There was as much variation in composition among kick sample points in a riffle as there was between reaches of a stream. Ordination based on the composition of the invertebrate community showed that in some cases (Avon River, Fish Creek, Phelan Creek) upstream and downstream reaches were well differentiated while in other streams (Dingman Creek, Kintore Creek, Waubuno Creek) there was as much variation among riffles and kick sample points as there was between upstream and downstream reaches (Fig. 3). In a couple of cases (Gregory Creek, Medway Creek), a particular riffle had communities distinct from the two other riffles at that reach and the three riffles at the other reach.

Substrate varied mostly at the reach (Substrate PC1) and stream and reach (Substrate PC2) scales, with little variation observed among riffles at a reach or among points within a riffles (Table 4). Habitat characteristics varied much more (Habitat PC1 and PC3) or almost as much (Habitat PC2) between reaches within a stream as they did among streams (Table 4).

The total correlation of biota and substrate showed greater taxonomic richness and pollution tolerance in areas with finer substrate (i.e., riffles with more gravel and not so much cobble). Most of this correlation was at larger spatial scales of stream and reach, rather than the smaller scales riffles and kick samples within riffles (Table 6). Correlation between habitat assessment and biota was more prominent at the among stream than the between reach scale (Table 7). Counterintuitively, there tended to be fewer, more pollution tolerant taxa in streams with a variety of velocity and depth regimes and treed riparian vegetation.

\section{Discussion}

We have illustrated in our study of 10 streams in a highly agricultural area (median agriculture land cover $\sim 90 \%$ ) that stream ecosystems sampled at the within riffle grain primarily vary at larger spatial scales, including the scale of the stream 
itself. This included both summary indices that described the diversity of the benthic invertebrate community (S, taxonomic richness), its tolerance of organic pollution (BI, the biotic index), and the taxonomic composition of the community (BrayCurtis distance of the community from the mean at a given scale). This is not to deny or ignore variation, sometimes statistically significant, at smaller spatial scales in these descriptors of the community. It just argues that a credible assessment of a set of sites in a given area can be effectively carried out if one reach per stream is sampled. Important differences among streams will be detected by such a sampling design, particularly with respect to the sort of descriptors used for assessment. This is reassuring, since of course the status quo of environmental assessment is to sample but one site per stream, and relate the biota found at that site to that expected in reference condition (Bailey et al., 2004 ). This is at odds with Heino et al. (2004), who in a multiscale, nested design study similar to ours found most of the variability in benthic invertebrate communities at smaller spatial scales and warned (a)

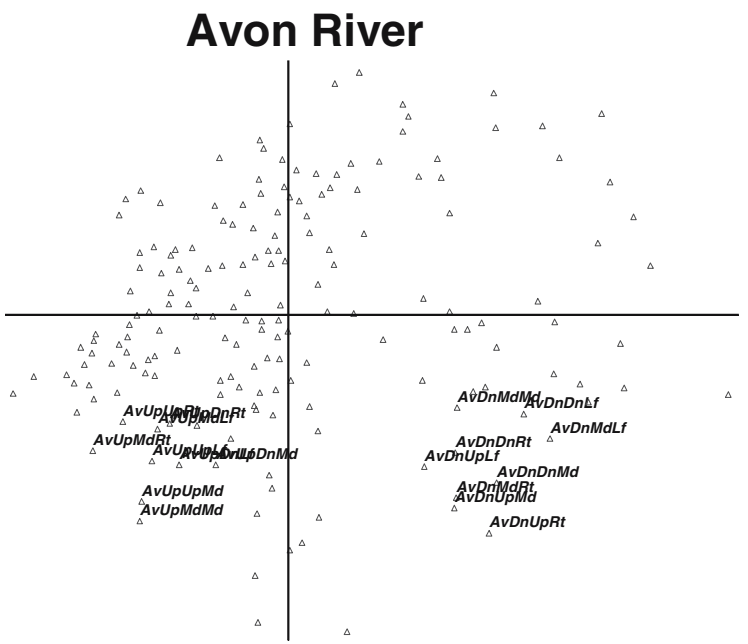

Fish Creek

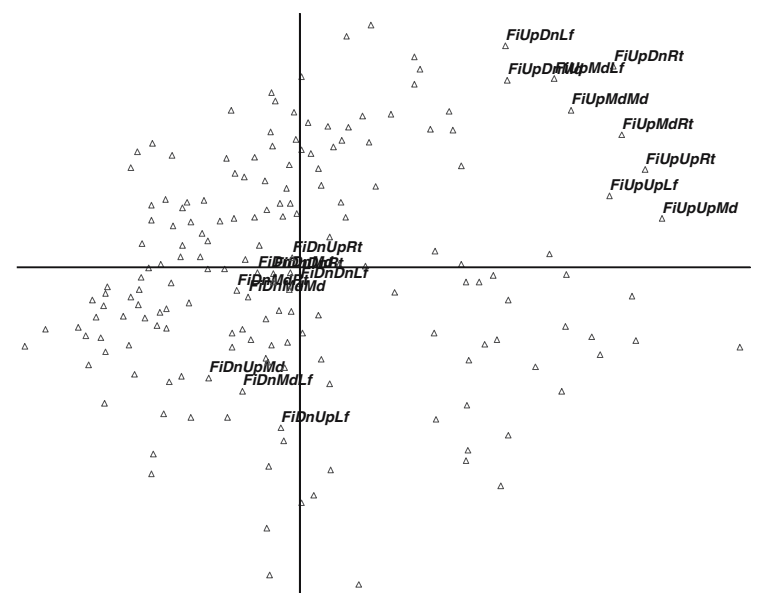

Fig. 3 Non-metric Multidimensional Scaling (NMDS) ordination plots of the 180 benthic invertebrate communities based on Bray-Curtis distances among communities calculated with the proportions of each taxon in the community. In each of the 10 plots, we plot the same

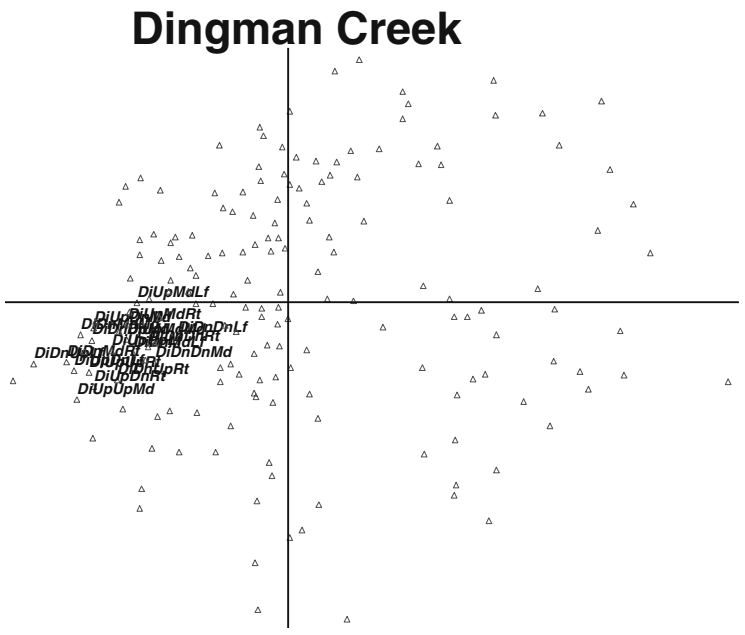

Gregory Creek

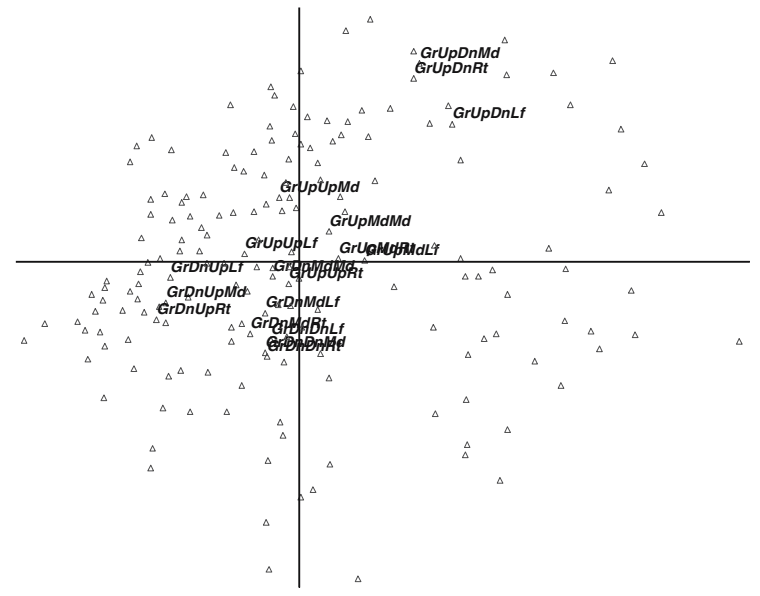

points but label communities from the stream indicated. The label characters describe the Stream, Reach, Riffle, and Point (e.g., "AvDnUpRt" is from the Avon River, the downstream reach, the furthest upstream riffle, and the right hand point within this riffle) 

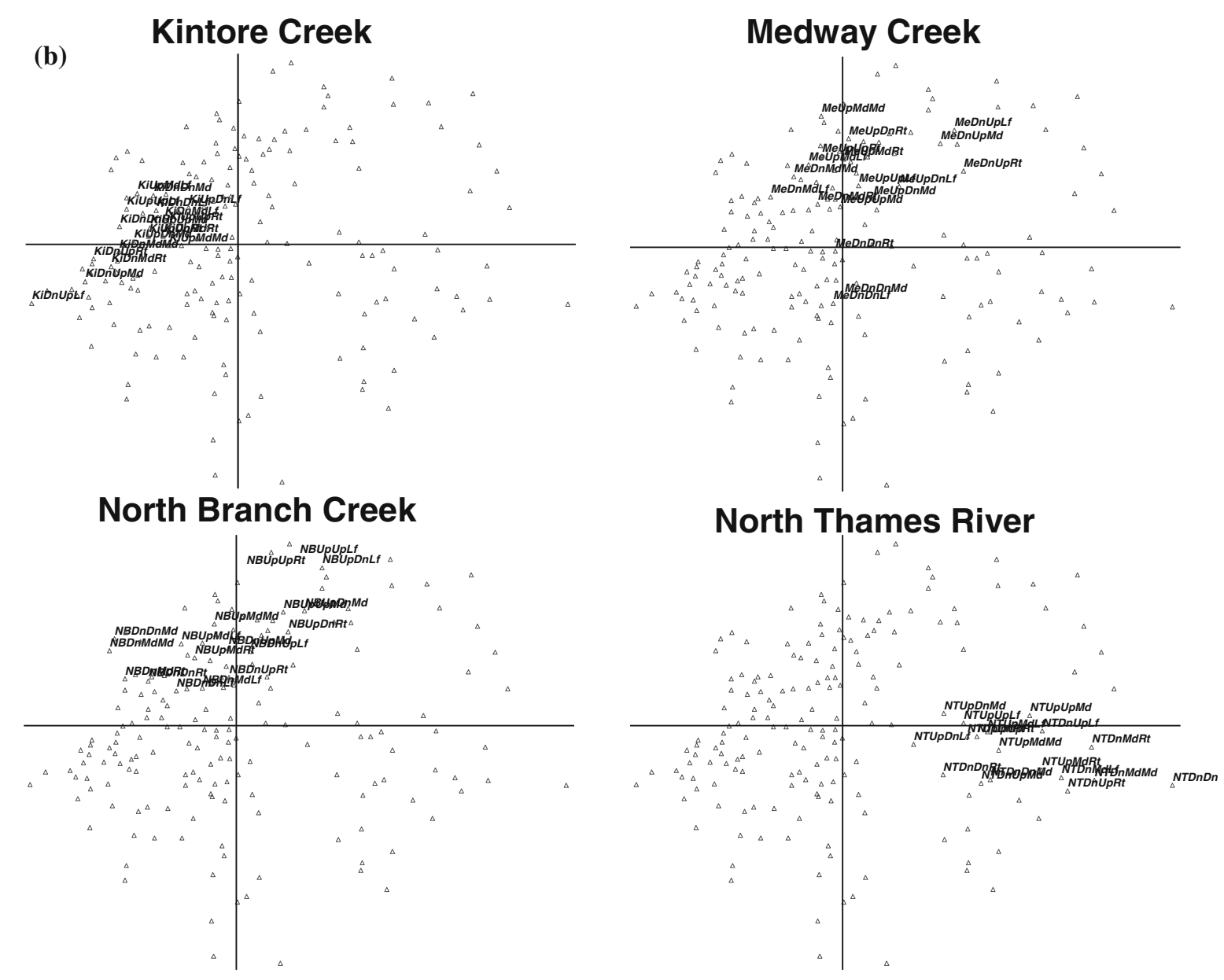

(c) Phelan Creek

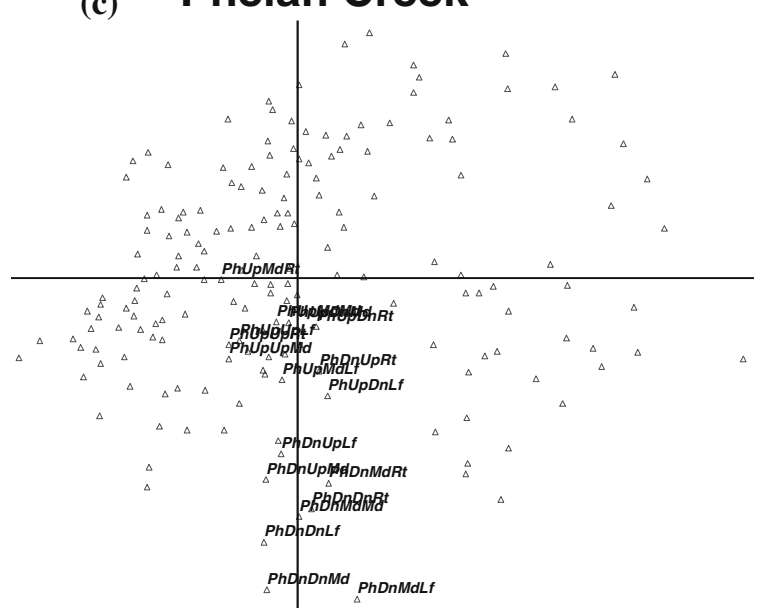

\section{Waubuno Creek}

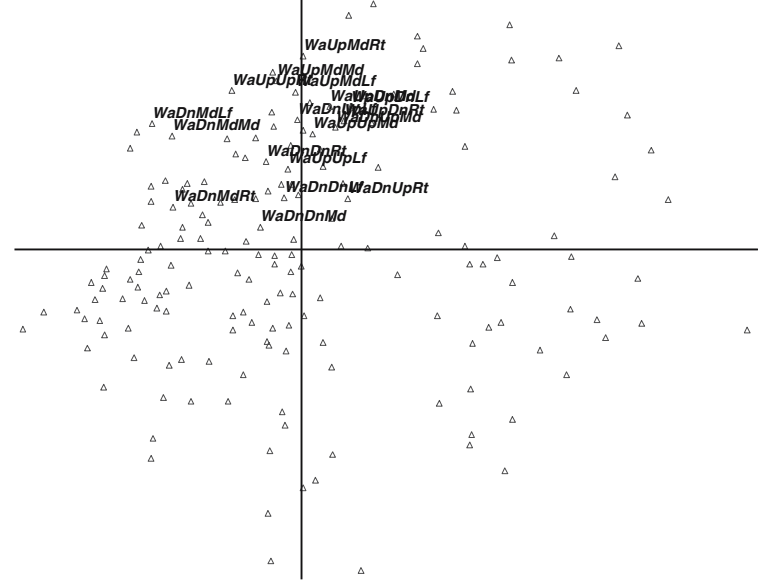

Fig. 3 continued 
Table 6 Hierarchical covariation of benthic macroinvertebrate communities and the substrate particle size distribution

\begin{tabular}{|c|c|c|c|c|}
\hline \multicolumn{5}{|c|}{ Total correlation } \\
\hline & S & $\mathrm{BI}$ & Substrate PC1 & Substrate PC2 \\
\hline S (richness) & 1 & 0.11 & -0.20 & -0.030 \\
\hline BI (tolerance) & & 1 & -0.40 & -0.039 \\
\hline Substrate PC1 & & & 1 & 0 \\
\hline Substrate PC2 & & & & 1 \\
\hline \multicolumn{5}{|c|}{ Among streams correlation } \\
\hline & $\mathrm{S}$ & $\mathrm{BI}$ & Substrate PC1 & Substrate PC2 \\
\hline S (richness) & 1 & 0.17 & -0.42 & -0.07 \\
\hline BI (tolerance) & & 1 & -0.58 & 0.10 \\
\hline Substrate PC1 & & & 1 & 0.15 \\
\hline Substrate PC2 & & & & 1 \\
\hline \multicolumn{5}{|c|}{ Between reaches correlation } \\
\hline & $\mathrm{S}$ & $\mathrm{BI}$ & Substrate PC1 & Substrate PC2 \\
\hline S (richness) & 1 & 0.49 & -0.35 & 0.04 \\
\hline BI (tolerance) & & 1 & -0.57 & -0.31 \\
\hline Substrate PC1 & & & 1 & 0.10 \\
\hline Substrate PC2 & & & & 1 \\
\hline \multicolumn{5}{|c|}{ Among riffles correlation } \\
\hline & $\mathrm{S}$ & $\mathrm{BI}$ & Substrate PC1 & Substrate PC2 \\
\hline S (richness) & 1 & 0.002 & -0.02 & -0.16 \\
\hline BI (tolerance) & & 1 & -0.17 & -0.07 \\
\hline Substrate PC1 & & & 1 & -0.28 \\
\hline Substrate PC2 & & & & 1 \\
\hline \multicolumn{5}{|c|}{ Within riffles correlation } \\
\hline & $\mathrm{S}$ & $\mathrm{BI}$ & Substrate PC1 & Substrate PC2 \\
\hline S (richness) & 1 & -0.035 & 0.017 & 0.13 \\
\hline BI (tolerance) & & 1 & 0.006 & -0.02 \\
\hline Substrate PC1 & & & 1 & -0.06 \\
\hline Substrate PC2 & & & & 1 \\
\hline
\end{tabular}

Correlations at each scale are derived from the sum of squares and cross-products at that scale, divided by the degrees of freedom, then standardized by the standard deviation at that scale of the two variables in the correlation. Bold faced correlations (absolute value $>0.2$ ) indicate what we considered interpretable correlations

of inadequate replication in bioassessments. Unlike our study, Heino et al. (2004) were concerned with abundance measures, including abundance of functional feeding groups, rather than commonly used measures of the health of a community (diversity, tolerance). They may indeed be correct in suggesting caution if one is wanting to characterize the functional structure of the ecological community rather than its response to stressors in the environment.

A continuing, critical part of pure stream ecology, and an increasingly important aspect of applied, assessment stream ecology, is characterization of relationships between the stream envi- ronment and stream biota. This study, in the same manner as Bailey (1988), uses a description of the biota observed at a single grain size (the point within a riffle) to measure and characterize correlations with the environment at the same grain size (for substrate) and a larger grain size (the reach, for habitat assessment). These correlations were quantified at the various spatial scales of the study design. We found that correlations between the biota and its community tended to be most prominent at larger scales (the stream or at least the reach). This again bodes well for the typical single reach per stream assessment study. It provides hope that important correlations between the environment of the stream and its biota will be detected even if just one riffle at one reach per stream is sampled. Johnson et al. (2004) looked exclusively at community composition in stony bottomed streams (and lakes) in a geographically and ecologically much larger study than ours. They found that the greatest strength of correlation between the community and its environment was at smaller scales of ecosystem (like our stream scale) and habitat descriptors rather than large scale, landscape and regional descriptors.

It is an ecological truism to assert that ecosystems are hierarchically structured. In stream ecology, particularly that aspect concerned with the environmental assessment of streams, we tend to deal with this in two ways:

(i) Mention the importance of scale and hierarchies and then create studies that have a mixture of scales of data acquisition (e.g., the field sampling site), data analysis (e.g., the catchment area of the site, or perhaps the site), and interpretation and action as a result of the study (e.g., the stream as a whole)

(ii) Make the overarching goal of the study to find the right scales or holons for stream ecology, firmly rooted in hierarchy theory (e.g., Parsons et al., 2004a, 2004b).

In this study, we have purposefully avoided an assertion as to the correct scales to sample a stream, or the holons that exist in the ecological hierarchy of stream ecosystems (cf. Parsons et al., 2004). We accept, of course, that the spatial and temporal scales that we design our studies and 
Table 7 Hierarchical covariation of benthic macroinvertebrate communities and the habitat assessment scores

Total correlation

\begin{tabular}{llllll}
\hline & S & BI & Habitat PC1 & Habitat PC2 & Habitat PC3 \\
\hline S (richness) & 1 & 0.23 & 0.14 & $\mathbf{- 0 . 2 9}$ & $\mathbf{0 . 2 6}$ \\
BI (tolerance) & & 1 & 0.08 & 0.23 & 0.016 \\
Habitat PC1 & & 1 & 1 & 0 \\
Habitat PC2 & & & 0 & 1
\end{tabular}

Among streams correlation

\begin{tabular}{|c|c|c|c|c|c|}
\hline - & S & $\mathrm{BI}$ & Habitat PC1 & Habitat PC2 & Habitat PC3 \\
\hline $\mathrm{S}$ (richness) & 1 & 0.17 & 0.12 & -0.37 & 0.32 \\
\hline BI (tolerance) & & 1 & 0.02 & 0.29 & -0.036 \\
\hline Habitat PC1 & & & 1 & 0.031 & 0.002 \\
\hline Habitat PC2 & & & & 1 & -0.18 \\
\hline Habitat PC3 & & & & & 1 \\
\hline \multicolumn{6}{|c|}{ Between reaches correlation } \\
\hline & $\mathrm{S}$ & $\mathrm{BI}$ & Habitat PC1 & Habitat PC2 & Habitat PC3 \\
\hline S (richness) & 1 & 0.49 & 0.20 & 0.002 & 0.16 \\
\hline BI (tolerance) & & 1 & 0.17 & 0.030 & 0.20 \\
\hline Habitat PC1 & & & 1 & -0.048 & -0.004 \\
\hline Habitat PC2 & & & & 1 & 0.41 \\
\hline Habitat PC3 & & & & & 1 \\
\hline
\end{tabular}

Correlations at each scale are derived from the sum of squares and cross-products at that scale, divided by the degrees of freedom, then standardized by the standard deviation at that scale of the two variables in the correlation. Bold faced correlations (absolute value $>0.2$ ) indicate what we considered interpretable correlations

analyse and interpret our data will affect the observations and conclusions we make. But rather than seeking, potentially in vain, scales that comprise the structure and function of larger scales and constrain the structure and function of smaller scales (what hierarchy theorists such as Parsons et al., (2004) would call holons), we use arbitrary, traditional observation scales (stream, reach, riffle, point) and let the data tell us how the ecosystem varies, and how the environment and biota covary. We see no utility in imposing a theoretical model, even if at least partially based on known functions of the ecosystem (e.g., geomorphological processes), on the hierarchical patterns of ecosystems observed in nature. In nature, holons form a continuum of two-way doors in a long and convoluted network of hallways. So we feel the most productive approach to understanding stream ecosystems is awareness of the doorway one is at or near when asking a certain question (e.g., "Is this stream OK?", "What controls crayfish distribution among points at this site?"), and at which doorways one can go to collect data that will answer such questions most efficiently.

Acknowledgements We thank Adam Yates for useful comments on an initial draft of this work. Tara Smith was invaluable in the field. The Upper Thames River Conservation Authority provided logistical support and unpublished data. This study was funded by an NSERC Discovery Grant to R.C. Bailey.

\section{References}

Bailey, R. C. 1988. Correlations between species richness and exposure-freshwater mollusks and macrophytes. Hydrobiologia 162(2): 183-191.

Bailey, R. C, R. H. Norris \& T. B. Reynoldson, 2004. Bioassessment of freshwater ecosystems using the reference condition approach. Springer, $184 \mathrm{pp}$.

Barton, D. R., 1996. The use of Percent Model Affinity to assess the effects of agriculture on benthic invertebrate communities in headwater streams of southern Ontario, Canada. Freshwater Biology 36: 397-410.

Boyero, L. \& R. C. Bailey, 2001. Organization of macroinvertebrate communities at a hierarchy of spatial scales in a tropical stream. Hydrobiologia 464: 219225. 
Frissell, C. A., W. J. Liss, C. E. Warren \& M. D. Hurley, 1986. A hierarchical framework for stream habitat classification - viewing streams in a watershed context. Environmental Management 10: 199-214.

Hawkins, C. P., J. L. Kershner, P. A. Bisson, M. D. Bryant, L. M. Decker, S. V. Gregory, D. A. Mccullough, C. K. Overton, G. H. Reeves, R. J. Steedman \& M. K. Young, 1993. A hierarchical approach to classifying stream habitat features. Fisheries 18: 3-12.

Heino, J., P. Louhi \& T. Muotka, 2004. Identifying the scales of variability in stream macroinvertebrate abundance, functional composition and assemblage structure. Freshwater Biology 49(9): 1230-1239.

Hilsenhoff, W. L., 1987. An improved biotic index of organic stream pollution. Great Lakes Entomologist 20: 31-39.

Imhof, J. G., J. Fitzgibbon \& W. K. Annable, 1996. A hierarchical evaluation system for characterizing watershed ecosystems for fish habitat. Canadian Journal of Fisheries and Aquatic Sciences 53: 312-326.

Johnson, R. K., W. Goedkoop, L. Sandin, 2004. Spatial scale and ecological relationships between the macroinvertebrate communities of stony habitats of streams and lakes. Freshwater Biology 49(9): 11791194.

Marchant, R., 1989. A subsampler for samples of benthic macroinvertebrates. Bulletin of the Australian Society for Limnology 12: 49-52.

Merritt, R. W. \& K. W. Cummins, 1995. Aquatic Insects of North America: An Introduction. Dubuque : Kendall/ Hunt Publishing Company Publisher Record.

Minshall, G. W. \& R. C. Petersen, 1985. Towards a theory of macroinvertebrate community structure in stream ecosystems. Archiv für Hydrobiologie 104: 49-76.

Parsons, M., M. C. Thoms \& R. H. Norris, 2003. Scales of macroinvertebrate distribution in relation to the hierarchical organization of river systems. Journal of the North American Benthological Society 22: 105-122.

Parsons, M., M. C. Thoms \& R. H. Norris, 2004a. Using hierarchy to select scales of measurement in multiscale studies of stream macroinvertebrate assemblages. Journal of the North American Benthological Society 23(2): 157-170.
Parsons, M., M. C. Thoms \& R. H. Norris, 2004b. Development of a standardised approach to river habitat assessment in Australia. Environmental Monitoring and Assessment 98(1-3): 109-130.

Plafkin, J. L., M. T. Barbour, K. D. Porter, S. K. Gross \& R. M. Hughes, 1989. Rapid bioassessment protocols for use in streams and rivers. Benthic macroinvertebrates and fish. EPA/444/4-89/001. Office of Water Regulations and Standards, U.S. Environmental Protection Agency, Washington, D.C.

Thorp, J. H. \& A. P. Covich, 1991. Ecology and Classification of North American Freshwater Invertebrates. San Diego: Elsevier Science \& Technology Books Publisher Record.

Townsend, C. R., B. J. Downes, K. Peacock \& C. J. Arbuckle, 2004. Scale and the detection of land-use effects on morphology, vegetation and macroinvertebrate communities of grassland streams. Freshwater Biology 49: 448-462.

Underwood, A. J. \& M. G. Chapman, 1998. A method for analysing spatial scales of variation in composition of assemblages. Oecologia 117: 570-578.

Vannote, R. L., G. W. Minshall, K. W. Cummins, J. R. Sedell \& C. E. Cushing, 1980. The river continuum concept. Canadian Journal of Fisheries and Aquatic Sciences 37: 130-137.

Wiederholm, T., 1983. Chironomidae of the Holarctic region. Part 1. Larvae. Entomologica Scandinavica Suppl. 19: 1-457.

Wiens, J. A., 2002. Riverine landscapes: taking landscape ecology into the water. Freshwater Biology 47: 501515.

Wiggins, G. B, 1995. The Larvae of the North American Caddisfly Genera (Trichoptera). Toronto: University of Toronto Press Publisher Record.

Yates, A. G. \& R. C. Bailey, 2006. The stream and its altered valley: Integrating landscape ecology into environmental assessments of agro-ecosystems. Environmental Monitoring and Assessment 114(1-3): 257 271. 